\title{
IMPLEMENTASI UNDANG-UNDANG REPUBLIK INDONESIA NOMOR 24 TAHUN 2011 TENTANG BADAN PENYELENGGARA JAMINAN SOSIAL DI RUMAH SAKIT BHAYANGKARA PALEMBANG
}

\section{IMPLEMENTATION OF LAW NUMBER 24 YEAR OF 2011 ON HEALTHCARE AND SOCIAL SECURITY AGENCY AT BHAYANGKARA HOSPITAL, PALEMBANG}

\author{
Yofitri Heny Wahyuli \\ Sekolah Tinggi Ilmu Administrasi (STIA) Satya Negara Palembang \\ J1. Sukatani 3, 8 Ilir Kecamatan Ilir Timur II, Kota Palembang, \\ Sumatera Selatan, Indonesia \\ e-mail: vivin_khanza@yahoo.com
}

Diserahkan: 02/02/2021; Diperbaiki: 17/05/2021; Disetujui: 23/05/2021

DOI: $10.47441 / j k p . v 16 i 1.144$

\begin{abstract}
Abstrak
Pelaksanaan jaminan sosial diatur dalam UU Nomor 24 Tahun 2011 tentang Badan Penyelenggara Jaminan Sosial (BPJS). Meski dalam pelaksanaanya sudah cukup baik, tapi masih ada hal-hal yang belum berjalan secara optimal. Penelitian ini bertujuan untuk mengetahui bagaimana implementasi UU Nomor 24 Tahun 2011 di Rumah Sakit Bhayangkara Palembang. Metode penelitian ini bersifat kualitatif. Data primer dikumpulkan melalui observasi dan wawancara, sedangkan data sekunder diperoleh dari dokumentasi dan studi pustaka yang relevan dengan objek penelitian. Parameter yang diukur berdasarkan model implementasi kebijakan yang dikembangkan oleh Edward III meliputi komunikasi, sumber daya, disposisi, dan struktur organisasi. Hasil penelitian menunjukkan bahwa komunikasi mengenai UU Nomor 24 Tahun 2011 di RS. Bhayangkara Palembang sudah baik, meliputi sosialisasi UU maupun adanya alat pendukung poster pemberitahuan terkait dengan BPJS. Sumber daya meliputi sikap pegawai yang ramah dan sopan santun, pelayanan yang diberikan memuaskan dan alurnya mudah diikuti. Di aspek disposisi semua implementor yang ada di RS Bhayangkara memiliki sifat jujur, berkomitmen, dan demokratis. Adapun beberapa kendala yang ada dalam implementasi UU Nomor 24 Tahun 2011 antara lain ketersediaan SDM yang dimiliki Rumah Sakit Bhayangkara Palembang tidak sebanding dengan jumlah pasien yang berobat, peralatan medis belum lengkap, proses klaim BPJS masih tidak efisien, dan adanya tunggakan pembayaran dari pihak BPJS.
\end{abstract}

Kata Kunci: Implementasi Undang-Undang, BPJS, Pelayanan Rumah Sakit

\section{Abstract}

The implementation of social security is regulated in Law Number 24 of 2011 on Healthcare and Social Security Agency (hereinafter abbreviated BPJS). Although it has been implemented quite well, there are still things that have not been done optimally. This study aims to determine how the implementation of Law Number 24 of 2011 at Bhayangkara Hospital, Palembang. This research method is qualitative, primary data were collected through observation and interviews. Parameters measured based on the policy implementation model developed by Edward III include communication, resources, disposition, and organizational structure. The results showed that the communication was good, both from the socialization and the existence of supporting tools for notification posters related to BPJS. Resources include friendly employee attitudes and courtesy, the services provided are satisfying and the flow is easy to follow. In the aspect of disposition, all implementers at Bhayangkara Hospital are honest, committed, and democratic. Some of the problems that exist are the lack of human resources at Bhayangkara Hospital compared to the 
number of patients, lack of medical equipment, the BPJS claim process is still inefficient, and the existence of arrears in payments from the BPJS.

Keywords: Implementation of Law, BPJS, Hospital Services.

\section{PENDAHULUAN}

Tujuan sebuah negara adalah memberikan kesejahteraan kepada seluruh rakyatnya. Siapapun dan apapun statusnya, berhak mendapatkan kesejahteraan dalam hidupnya, termasuk kesejahteraan dalam hal kesehatan. Keberadaan institusi bernama Badan Penyelenggara Jaminan Sosial (BPJS) adalah salah satu cara untuk dapat memenuhi kebutuhan dasar hidup yang layak dan meningkatkan martabatnya menuju terwujudnya masyarakat Indonesia yang sejahtera, adil dan makmur. Sebelum BPJS dibentuk, telah ada program Jaminan Sosial Tenaga Kerja (JAMSOSTEK) berdasarkan Undang-Undang Nomor 3 Tahun 1992. JAMSOSTEK mencakup program jaminan pemeliharaan kesehatan, jaminan kecelakaan kerja, jaminan hari tua, dan jaminan kematian bagi tenaga kerja. Akan tetapi pelayanan JAMSOSTEK dinilai hanya mencakup sebagian kecil masyarakat. Sebagian besar rakyat belum memperoleh perlindungan yang memadai.

Rumah Sakit Bhayangkara Palembang adalah rumah sakit yang berlokasi di Kecamatan Kemuning, Kota Palembang, Sumatera Selatan, yang secara administrasi merupakan rumah sakit milik dari Polri yang diberi nama "Balai Pengobatan Tri Sakti". Bangunan Rumah Sakit Bhayangkara Palembang awalnya merupakan sarana pelayanan kesehatan yang bertujuan untuk memberikan pelayanan kesehatan pada karyawannya pada jaman penjajahan sekitar tahun 1975, dan diresmikan langsung oleh Kapolda Sumatera Selatan, Irjen Pol. Prof. Eko Indra Heri. Sarana pelayanan kesehatan tersebut sekarang dibawah kepemilikan Polri, sarana pelayanan kesehatan tersebut dirubah atau dikembangkan menjadi rumah sakit yang diberi nama Rumah Sakit Polri tersebut menjadi RS Bhayangkara Mohammad Hasan yang lokasinya di Jalan Jendral Sudirman Km 4,5 Kecamatan Kemuning Palembang (Rumah Sakit Bhayangkara 2020). Seiring dengan adanya perkembangan masyarakat, Rumah Sakit Bhayangkara Palembang terasa kurang memadai baik dari segi bangunan maupun dari segi kualitas pelayanan. Permasalahan yang ada adalah kondisi geografis di sekitar Rumah Sakit Bahyangkara Palembang tidak memungkinkan untuk melakukan penambahan layanan baru karena keterbatasan lahan. Gedung tambahan untuk ruang isolasi, CSSD dan Loundry (Central Sterile Supply Departement), Instalasi Gizi, dan ruang CT Scan tidak dapat dibangun karena tidak memenuhi persyaratan dan keterbatasan dana.

Berbagai upaya telah ditempuh oleh pemerintah untuk memenuhi tuntutan masyarakat atas fasilitas kesehatan yang berkualitas dan terjangkau. Pelayanan yang diberikan rumah sakit harus berkualitas dan memenuhi 5 (lima) dimensi mutu utama yaitu: tangibles, reliability, resvonsiveness, assurance, dan emphaty (Fahriadi, 2011). Bhayangkara Palembang dituntut untuk memberikan pelayanan yang lebih baik kepada masyarakat, terutama dalam hal penyelenggaraan jaminan sosial kesehatan masyarakat. Selama ini pelayanan BPJS masih kurang baik di mata masyarakat. Masyarakat pemegang kartu BPJS masih memiliki keluhan terhadap pelayanan administrasi, tenaga kesehatan, sarana dan prasarana Rumah Sakit, obat, biaya tambahan, dan layanan lainnya. Masalah kepuasan pasien sebagai tolok ukur tingkat kualitas pelayanan kesehatan merupakan masalah yang kompleks dan tidak mudah untuk dibatasi.

Sebagaimana telah dikatakan William N. Dunn, bahwa "kebijakan sebagai serangkaian tindakan/kegiatan yang diusulkan seseorang, kelompok atau pemerintah dalam suatu lingkungan tertentu yang terdapat hambatan-hambatan (kesulitan-kesulitan) dan kesempatan-kesempatan terhadap pelaksanaan usulan kebijaksanaan tersebut dalam rangka mencapai tujuan tertentu. Pendapat ini juga menunjukkan bahwa ide kebijakan melibatkan perilaku yang memiliki maksud dan tujuan merupakan bagian yang penting dari definisi 
kebijakan, karena bagaimanapun kebijakan harus menunjukan apa yang sesungguhnya dikerjakan daripada apa yang diusulkan dalam beberapa kegiatan pada suatu masalah".

Rendahnya mutu pelayanan dapat disebabkan oleh faktor input (kurangnya fasilitas, peralatan, tenaga dokter ahli, dana, dan sebagainya). Beberapa faktor yang mendukung mutu pelayanan yang rendah di Rumah Sakit di antaranya jumlah dokter spesialis, kuantitas dan kualitas perawat, serta alokasi pendanaan masih memprioritaskan pada fisik dan peralatan. Kecilnya alokasi dana untuk operasional Rumah Sakit disertai dengan tingginya target pemasukan PAD merupakan salah satu alasan kecilnya dana untuk peningkatan mutu pelayanan (Arifin, Darmawansyah and Ilma 2011). Studi pendahuluan yang dilakukan pada bulan Maret 2020 untuk mencari tahu lebih mendalam bagaimana pelayanan kesehatan yang diterima oleh pasien menunjukkan adanya ketidakpuasan terhadap petugas yang kurang ramah dalam memberi pelayanan dan arahan mengenai persyaratan administrasi BPJS. Hal ini menyebabkan pasien merasa berat hati melakukan arahan yang diberikan karena pelayanan petugas kurang baik dalam penyampaiannya. Berdasarkan hasil wawancara, pasien menganggap bahwa peserta BPJS mendapat pelayanan dan perlakuan yang berbeda dengan pasien lain yang bukan pengguna layanan kesehatan BPJS, terkait persyaratan administrasi yang cukup rumit, meskipun sebenarnya pelayanan yang diberikan sama. Permasalahan yang umum dijumpai dalam alur pelayanan BPJS di Rumah Sakit antara lain berkas klaim yang tidak lengkap, banyaknya klaim susulan, ketidaksesuian tarif yang diajukan rumah sakit dengan yang dibayarkan BPJS, kejanggalan pengkodean diagnosis penyakit, hingga keterlambatan pembayaran klaim oleh BPJS kesehatan. Hal ini berdampak negatif bagi peserta BPJS yang tentunya sudah melakukan kewajibannya dengan membayarkan iuran pada setiap bulan. Berdasarkan wawancara dengan petugas rumah sakit diketahui bahwa belum terdapat tindak lanjut terhadap keluhan pasien tersebut. Berdasarkan hal ini, maka penelitian ini bertujuan untuk menganalisis implementasi UU Nomor 24 Tahun 2011 di RS Bhayangkara Palembang.

\section{METODE PENELITIAN}

Penelitian ini dilaksanakan pada bulan Maret - Juni 2020 di Rumah Sakit Bhayangkara Palembang. Pendekatan yang digunakan adalah kualitatif. Pengumpulan data primer dilakukan melalui wawancara mendalam dengan petugas rumah sakit dan observasi terhadap pasien rawat inap. Teknik pengambilan sampel adalah purposive sampling, Analisis data dilakukan secara deskriptif berdasarkan model Implementasi Kebijakan oleh Edward III (2010) dalam Directy and indirect Impact on Implementation. Pendekatan yang digunakan dalam menganalisis implementasi dimulai dari kondisi abstrak dan sebuah pertanyaan tentang apakah syarat agar implementasi kebijakan dapat berhasil. Ada 4variabel dalam melihat implementasi kebijakan publik yang dikemukakan oleh Edwards III, yaitu komunikasi (communications), sumber daya (resources), sikap (dispositions atau attitudes), dam struktur birokrasi (bureucratic structure). Keempat faktor ini harus dilaksanakan secara simultan karena antara satu dengan yang lainnya memiliki hubungan yang erat (Mulyadi, Gedeona and Nurafandi 2016).

\section{HASIL DAN PEMBAHASAN}

Mutu pelayanan kesehatan di rumah sakit yang baik mempengaruhi tingkat kepuasan pasien. Hal ini tidak terlepas dari peran tenaga medis maupun tenaga non-medis di rumah sakit. Hasil penelitian ini sejalan dengan penelitian Amalia (2015) yang menunjukkan bahwa ada hubungan yang bermakna antara kehandalan, daya tanggap, jaminan, empati dan bukti fisik pelayanan dengan kepuasan pasien dan dari kelima dimensi mutu pelayanan tersebut variabel bukti fisik memiki pengaruh paling dominan. Penelitian ini sejalan dengan penelitian sebelumnya yang dilakukan oleh Syaputra (2015), bahwa ada hubungan antara mutu pelayanan BPJS Kesehatan terhadap kepuasan pasien. Mutu 
pelayanan kurang baik membuat pasien merasa kurang puas. Dengan mengetahui kepuasan pasien, manajemen BPJS kesehatan dan Rumah Sakit dapat meningkatkan mutu pelayanan. Hasil penelitian ini sejalan dengan penelitian yang dilakukan oleh Abidin (2016) bahwa ada pengaruh antara ketanggapan petugas kesehatan dengan keputusan menggunakan jasa pelayanan rawat jalan. Sejalan juga dengan penelitian yang dilakukan oleh Suparta, dkk (2018), yang menyatakan bahwa ada hubungan mutu pelayanan kesehatan ditinjau dari segi ketanggapan dengan kepuasan pasien pengguna layanan kesehatan gratis.

\section{Komunikasi}

BPJS selaku badan hukum publik memiliki kekuasaan dan kewenangan untuk mengatur publik melalui kewenangan membuat peraturan-peraturan yang mengikat publik. BPJS terdiri dari BPJS Kesehatan dan BPJS Ketenagakerjaan, sebagaimana yang termaktub dalam Pasal 5 Undang-Undang Nomor 24 Tahun 2011. Adapun pelaksanaan perjanjian kerjasama antara Rumah Sakit Bhayangkara dengan BPJS Kesehatan dalam Program Jaminan Kesehatan Nasional (JKN) menggunakan dasar hukum Peraturan Presiden Nomor 12 Tahun 2013 dan Peraturan Menteri Kesehatan Nomor 71 Tahun 2013.

Berdasarkan hasil wawancara dengan pejabat Rumah Sakit Bhayangkara, segala langkah terkait keberadaan BPJS di Rumah Sakit. Bhayangkara Palembang telah berdasarkan Undang-undang, Peraturan Menteri Kesehatan, buku pedoman, petunjuk teknis (juknis), petunjuk pelaksanaan (juklak), serta nota kesepakatan $(\mathrm{MoU})$ antara pihak rumah sakit dengan BPJS. Sosialisasi yang telah dilakukan meliputi program BPJS Rumah Sakit Bhayangkara Palembang, prosedur pelayanan pasien rawat jalan dan rawat inap, dan syarat-syarat pembayaran. Sosialisasi tersebut dilakukan secara optimal dan dilaksanakan berdasarkan buku pedoman yang dikeluarkan langsung oleh Kepala Rumah Sakit Bhayangkara Palembang. Selain itu, kunjungan dari Tim Pemeriksaan Kesehatan Pusat rutin dilakukan untuk mengawasi jalannya implementasi UU Nomor 24 Tahun 2011.

\section{Sumber Daya}

Sumber daya tenaga kesehatan dan semua penunjang yang dimiliki Rumah Sakit Bhayangkara Palembang adalah sebagai berikut:

Tabel 1. Jumlah Dokter di Rumah Sakit Bhayangkara Palembang

\begin{tabular}{clc}
\hline No & \multicolumn{1}{c}{ Dokter } & Jumlah \\
\hline 1 & Dokter Sp.A (Spesialis Anak) & 2 \\
\hline 2 & Dokter Sp.OG (Spesialis Kebidanan dan Kandungan) & 5 \\
\hline 3 & Dokter Sp.PD ( Spesialis Penyakit Dalam) & 6 \\
\hline 4 & Dokter Sp.B (Spesialis Bedah) & 4 \\
\hline 5 & Dokter Sp.Rad (Spesialis Radiologi) & 1 \\
\hline 6 & Dokter Sp.RM (Spesialis Anestesiologi dan Reanemiasi) & 1 \\
\hline 7 & Dokter Sp.JP (Spesialis Jantung dan Pembuluh Darah) & 2 \\
\hline 8 & Dokter Sp.M (Spesialis Mata) & 3 \\
\hline 9 & Dokter Sp.THT ( Spesialis Telinga, Hidung dan Tenggorokan) & 14 \\
\hline 10 & Dokter Umum & 3 \\
\hline 11 & Dokter Gigi & $\mathbf{4 2}$ \\
\hline
\end{tabular}

Sumber: data sekunder yang diolah (2020) 
Tabel 2. Jumlah Ketenagaan lainnya di RS Bhayangkara Palembang

\begin{tabular}{|c|c|c|}
\hline No & Tenaga & Jumlah \\
\hline 1 & Perawat & 54 \\
\hline 2 & Bidan & 23 \\
\hline 3 & Farmasi & 2 \\
\hline 4 & Tenaga Kesehatan Lainnya & 70 \\
\hline 5 & Tenaga Non kesehatan & 20 \\
\hline & Jumlah & 169 \\
\hline
\end{tabular}

Sumber: data sekunder yang diolah (2020)

Tabel 3. Jumlah Tempat Tidur menurut Kelas

\begin{tabular}{|c|c|c|}
\hline No & 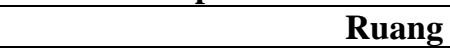 & Jumlah \\
\hline 1 & VVIP & 2 Kamar \\
\hline 2 & VIP & 6 Kamar \\
\hline 3 & VIP 1 & 11 Kamar \\
\hline 4 & VIP 2 & 12 Kamar \\
\hline 5 & VIP 3 & 3 Kamar \\
\hline 6 & ICU & 1 Kamar \\
\hline 7 & TT di IGD & 3 Kamar \\
\hline 8 & TT Bayi baru lahir & 10 Kamar \\
\hline 9 & TT Kamar Bersalin & 4 Kamar \\
\hline 10 & TT Ruang Operasi & 2 Kamar \\
\hline 11 & TT Ruang Isolasi & 2 Kamar \\
\hline & Jumlah & 56 Kamar \\
\hline
\end{tabular}

Sumber: data sekunder yang diolah (2020)

Hal tersebut sudah cukup sesuai dengan tipe RS Bhayangkara Palembang. Sumber daya manusia yang dimiliki tersebut mampu melaksanakan tugas dan kewajibannya sebagai petugas yang melayani kesehatan masyarakat, dan hasil penelitian menunjukkan bahwa petugas dapat memanfaatkan perangkat penunjang pekerjaan secara baik dan petugas cukup tanggap dalam merespon keluhan dari pasien, hal ini dapat menjadi pendukung pelayanan terhadap pasien rawat inap di rumah sakit Bhayangkara Palembang. Menurut Haryadi dan Solikhah (2013), penerapan sistem informasi merupakan suatu cara untuk menunjang proses pelayanan pasien. SDM memiliki peranan yang penting di dalam keberhasilan suatu sistem, disamping itu juga ditunjang dengan sarana dan prasarana yang memadai dan sudah menerapkan sistem informasi di dalam proses pelayanan pasien, termasuk di dalam pelayanan pendaftaran pasien rawat jalan. Namun terdapat beberapa kendala di dalam penerapannya, diantaranya seperti masalah SDM, sarana dan prasarana, serta laporan yang dihasilkan.

\section{Disposisi}

Salah satu faktor yang mempengaruhi efektifitas implementasi kebijakan adalah sikap implementor. Jika implementor setuju dengan bagian-bagian isi dari kebijakan, mereka akan melaksanakan dengan senang hati. Tetapi jika pandangan mereka berbeda dengan pembuat kebijakan maka proses implementasi akan mengalami banyak masalah. Dukungan dari pimpinan sangat mempengaruhi pelaksanaan program dapat mencapai tujuan secara efektif dan efisien. Wujud dari dukungan pimpinan ini adalah Menempatkan kebijakan menjadi prioritas program, penempatan pelaksana dengan orang-orang yang mendukung program, memperhatikan keseimbangan daerah, agama, suku, jenis kelamin dan karakteristik demografi yang lain. Disamping itu penyediaan dana yang cukup guna memberikan insentif bagi para pelaksana program agar mereka mendukung dan bekerja secara total dalam melaksanakan kebijakan/program. Menurut Edward III (dalam Riant Nugroho 2014), disposisi implementator dalam implementasi kebijakan dibedakan menjadi tiga hal yaitu : (a) respons implementator terhadap kebijakan, yang terkait dengan kemauan 
implementator untuk melaksanakan kebijakan publik; (b) kondisi, yakni pemahaman terhadap kebijakan yang telah ditetapkan; dan (c) intens disposisi implementator, yakni preferensi nilai yang dimiliki tersebut. Implementor di RS Bhayangkara Palembang sudah cukup baik dalam melaksanakan tugas dan fungsinya, terutama dalam kaitannya dengan BPJS.

\section{Stuktur Birokrasi/Organisasi}

Struktur birokrasi/organisasi yang tidak kondusif terhadap implementasi kebijakan akan menyebabkan ketidakefektifan pelaksanaan kebijakan. Struktur birokrasi/organisasi yang bertugas saat ini sudah membantu dalam pelayanan komunikasi dan alur birokrasi yang ada, sehingga dapat mendukung implementasi UU Nomor 24 Tahun 2011 di RS. Bhayangkara Palembang. Berdasarkan hasil wawancara dengan salah satu petugas rumah sakit, pelaksanaan di setiap ruangan sudah berjalan dengan teratur dan sesuai dengan Standard Operating Procedure (SOP) dalam pelayanan baik itu dalam alur prosedur antar petugas maupun terhadap pasien. SOP dalam implementasi UU Nomor 24 Tahun 2011 di RS Bhayangkara Palembang meliputi kejelasan petunjuk pelaksanaan yang diatur oleh Permenkes Nomor 28 Tahun 2014, Buku Pedoman tentang Sistem Pelayanan Jaminan Kesehatan Nasional (JKN) bagi Personel Militer, PNS, dan Keluarganya di Lingkungan TNI AD bagi Pemberi Pelayanan Kesehatan/Faskes, juknis dan juklak BPJS, serta $M o U$ Rumah Sakit Bhayangkara Palembang dengan BPJS.

Faktor-faktor yang Berpengaruh terhadap Implementasi UU Nomor 24 Tahun 2011 tentang BPJS di Rumah Sakit Bhayangkara Palembang

\section{Kelengkapan Sarana dan Prasarana Rumah Sakit}

Secara umum prasarana dan sarana adalah alat penunjang keberhasilan suatu proses upaya yang dilakukan di dalam pelayanan publik. Jika kedua hal ini tidak tersedia, maka semua kegiatan yang dilakukan tidak akan dapat mencapai hasil yang diharapkan. Prasarana dan sarana adalah merupakan seperangkat alat yang digunakan dalam suatu proses kegiatan baik alat tersebut adalah merupakan peralatan pembantu maupun peralatan utama, yang keduanya berfungsi untuk mewujudkan tujuan yang hendak dicapai. Prasarana yang harus tersedia dalam rumah sakit yaitu meliputi: (a) instalasi air; (b) instalasi mekanikal dan elektrikal; (c) instalasi gas medik; (d) instalasi uap; (e) instalasi pengelolaan limbah; (f) pencegahan dan penanggulangan kebakaran; (g) petunjuk, standar dan sarana evakuasi saat terjadi keadaan darurat; (h) instalasi tata udara, sistem informasi, dan komunikasi; dan (i) Ambulans (Rumah sakit Bhayangkara Palembang 2020). Semua prasarana tersebut harus memenuhi standar pelayanan, keamanan, serta keselamatan dan kesehatan kerja penyelenggaraan rumah sakit, untuk itu maka prasarana tersebut harus dalam keadaan terpelihara dan berfungsi dengan baik. Sarana dan prasarana di atas sebenarnya sudah ada di Rumah Sakit Bhayangkara Palembang, Akan tetapi masih ada beberapa keluhan dari pasien rawat inap seperti peralatan medis yang kurang lengkap sehingga pasien harus dirujuk ke rumah sakit lain karena keterbatasan peralatan medis, akses internet yang lambat sehingga menghambat akses informasi dan semua prosedur yang harus dilakukan secara daring, serta kurangnya loket pendaftaran sehingga sering terjadi tumpukan antrian.

\section{Administrasi BPJS}

Persyaratan untuk mengajukan klaim BPJS Kesehatan adalah seseorang yang telah berstatus tidak aktif sebagai karyawan, surat keterangan sudah berhenti bekerja, fotocopy KTP, Kartu Keluarga (KK), fotoku tabungan, foto diri ukuran 3x4 dan 4x6 sebanyak 4 (empat) rangkap, Fakta di lapangan masih banyak pasien BPJS Kesehatan yang tidak dapat melengkapi persyaratan administrasi. Hal ini menjadi dilema bagi pihak rumah sakit, di satu sisi pasien harus segera ditangani, akan tetapi jika persyaratan belum lengkap, klaim 
BPJS Kesehatan tidak dapat dilakukan. Untuk mencegah hal tersebut terulang kembali, sebaiknya diberikan keringanan persyaratan atau pemberian jangka waktu untuk melengkapi dokumen, agar pasien dapat segera mendapatkan tindakan medis tanpa memikirkan persyaratan administratif.

Selain kendala persyaratan administratif, faktor lain yang menjadi permasalahan adalah mekanisme untuk pengajuan klaim BPJS Kesehatan harus mendaftar terlebih dahulu di Puskesmas/ Klinik yang bekerjasama dengan BPJS Kesehatan, setelah itu baru dilakukan pemeriksaan/ diagnosa. Setelah mengetahui hasilnya dari pemeriksaan, baru Puskesmas/ Klinik memberikan rujukan ke rumah sakit yang ditunjuk. Hal tersebut sangat tidak efisien karena memerlukan alur dan waktu yang cukup Panjang. Idealnya, tata cara atau prosedur klaim BPJS Kesehatan lebih dipermudah. Misalkan pasien tidak perlu mendaftar ke Puskesmas/Klinik terlebih dahulu, karena sebagai anggota peserta BPJS Kesehatan pasien berhak mendapatkan pelayanan kesehatan yang diperlukan di semua fasilitas pelayanan kesehatan yang sudah bekerja sama dengan BPJS Kesehatan, dengan cukup membawa kartu anggota BPJS Kesehatan.

BPJS (Badan Penyelenggara Jaminan Sosial) Kesehatan merupakan lembaga pengelola dan Rumah Sakit selaku lembaga penyedia jasa pelayanan kesehatan dituntut untuk memberikan kualitas pelayanan yang baik kepada pengguna jasa (pasien)peserta jaminan, sehingga tingkat kepuasan dapat terwujud. Penelitian ini bertujuanuntuk menganalisis kualitas pelayanan BPJS dan kualitas pelayanan Rumah Sakit terhadap kepuasan pasien peserta program BPJS Kesehatan dengan indikator: Reliability, Daya Tanggap, Assurance, Empathy (Sri Rahayu, 2016).

Hasil temuan lain dari Trisna, Pramusinto, dan Lazuardi (2017) menunjukkan bahwa BPJS tidak sepenuhnya berjalan efektif karena terdapat beberapa kekurangan seperti peralatan labotarium dan tidak digunakannya alat hemodialisis (cuci darah). Identifikasi faktor yang berpengaruh secara internal adalah: (1) faktor mekanisme pencairan klaim BPJS (2) keuangan rumah sakit (3) faktor sarana prasarana (4) faktor sumber daya manusia.

\section{Daya Tanggap}

Aspek daya tanggap dimasukkan ke dalam kemampuan petugas kesehatan menolong pelanggan dari kesiapannya melayani sesuai prosedur dan bisa memenuhi harapan pasien. Pelayanan kesehatan yang responsif terhadap kebutuhan pasiennya kebanyakan ditentukan oleh sikap para front line staff. Mereka secara langsung berhubungan dengan para pengguna jasa dan keluarganya, baik melalui tatap muka, komunikasi non verbal langsung atau melalui telepon (Muninjaya 2015). Berdasarkan hasil penelitian diketahui dimensi mutu daya tanggap sudah berjalan dengan baik, hal ini sesuai dengan hasil wawancara dengan pasien yang merasa puas terhadap daya tanggap yang diberikan oleh petugas rumah sakit. Hal ini terlihat pada petugas ruang rawat inap yang cepat tanggap dalam membantu kebutuhan dan perawatan pasien, cepat datang jika tenaganya dibutuhkan di kamar pasien, dan memberikan informasi secara jelas dan mudah dimengerti oleh pasien. Hal ini sejalan dengan penelitian yang dilakukan oleh Musdalifah dan Fuad Hasan (2016), bahwa variabel daya tanggap petugas kesehatan sangat berpengaruh terhadap persepsi pasien tentang mutu pelayanan kesehatan.

\section{Realibilitas}

Aspek reliabilitas (reability) berkaitan dengan kemampuan suatu organisasi untuk menyampaikan layanan yang dijanjikan secara akurat sejak pertama kali dan kemampuan memberikan layanan yang dijanjikan dengan segera serta memuaskan. Pengguna jasa kesehatan akan memberikan penilaian untuk pelayanan jasa kesehatan. Berdasarkan hasil wawancara dengan salah satu staf Unit Admisi IGD di RS Bhayangkara Palembang, tingkat keandalan tenaga medis sudah cukup baik meliputi kemampuan memberikan layanan dengan segera, akurat, dan memuaskan kepada pasien. 


\section{Empati}

Berdasarkan wawancara dengan Kepala Ruangan Rekam Medis RS Bhayangkara Palembang, tenaga Kesehatan harus memiliki empati dengan cara menghargai pasien dan tidak membeda-bedakan dalam melakukan perawatan. Pada dasarnya penjiwaan empati sebagai dasar kepribadian tenaga medis adalah syarat mutlak. Empati para tenaga kesehatan di RS Bhayangkara Palembang sebagian besar sudah baik, terlihat pada keramahan dan kesabaran tenaga kesehatan dalam menangani pasien baik dalam ruang rawat inap, rawat jalan, maupun di unit pelayanan lainnya.

\section{Jaminan}

Aspek jaminan (assurance) berkenaan dengan pengetahuan dan kesopanan karyawan serta kemampuan mereka dalam menumbuhkan rasa percaya (trust) dan keyakinan pelanggan (confidence). Saat pasien harus menjalani rindakan medis tertentu, pasien pasti ingin mendapat jaminan bahwa tenaga kesehatan yang melayani benar-benar kompeten. Berdasarkan wawancara dengan Supervisor Instalasi Transportasi Ur-Jangum RS Bhayangkara, diketahui bahwa tenaga kesehatan harus dapat memberikan jaminan keyakinan kepada pasien bahwa mereka dapat dipercaya, dapat membantu pasien, dan bisa memberikan harapan kesembuhan. Pelayanan BPJS salah satunya memberikan manfaat jaminan dalam bentuk kepastian mendapatkan tindakan medis yang sesuai, dan dilakukan oleh tenaga medis yang kompeten. Selain itu BPJS juga menjamin kompensasi terhadap resiko kerugian, kerusakan, kematian, dan hal-hal yang mungkin akan ditanggung oleh pasien karena suatu peristiwa yang tidak terduga.

\section{Kenyamanan}

Salah satu yang dicari pasien dalam masa pengobatan adalah kenyamanan. Meski menggunakan jenis bantuan kesehatan seperti apa pun pasien pasti membutuhkan kenyamanan untuk proses penyembuhannya. Berdasarkan hasil wawancara dengan Subbag Assembling dan Administrasi, diketahui bahwa intervensi untuk rasa nyaman merupakan tindakan keperawatan dan ditujukan untuk mencapai kebutuhan kenyamanan penerima asuhan yang mencakup fisiologis, sosial, budaya, ekonomi, spiritual, lingkungan dan intervensi fisik. Intervensi keperawatan yang diberikan secara holistik dan diaplikasikan secara konsisten dan efektif untuk meningkatkan kenyamanan dari waktu-ke waktu. Tingkat kenyamanan di RS Bhayangkara Palembang sudah baik dilihat dalam hal kebersihan, keamanan, dan kepuasan pasien dalam menggunakan BPJS. Kenyamanan fasilitas yang ada di ruang rawat inap sudah cukup bagus. Meski demikian, masih ada keluhan sebagian pasien mengenai fasilitas kamar mandi dan panasnya suhu ruangan rawat inap.

Hasil penelitian yang dikemukakan oleh Wulandari (2018) mengatakan bahwa dari keenam dimensi mutu pelayanan kesehatan yakni dimensi efektif, dimensi efisien, dimensi akses, dimensi Patient-Centered, dimensi adil, dimensi aman menunjukkan tidak adanya perbedaan kepuasan pasien berdasarkan lama hari rawat. Begitu juga dilihat dari hasil penelitian Riswan (2020) ini menunjukkan bahwa ada hubungan yang bermakna pada variabel jaminan (assurance), empati (emphaty), dan bukti fisik (tangible) terhadap kepuasan pasien. Adapun pada variabel kehandalan (reliability) dan daya tanggap (responsiveness) tidak menunjukkan hubungan yang bermakna terhadap kepuasan pasien rawat inap peserta BPJS. 


\section{SIMPULAN DAN REKOMENDASI}

\section{Simpulan}

Implementasi UU Nomor 24 Tahun 2011 di Rumah Sakit Bhayangkara Palembang menunjukkan bahwa secara umum pelayanan yang diberikan sudah baik, tapi masih ada hal-hal yang belum berjalan secara optimal. Unsur komunikasi terlaksana dengan baik melalui sosialisasi UU Nomor 24 Tahun 2011 di RS Bhayangkara. Sumber daya (meliputi SDM, fasilitas, sarana dan prasarana) juga cukup baik, hanya saja masih ada permasalahan kualitas dan kuantitas peralatan medis yang rendah. Pada aspek disposisi, sikap dan komitmen implementor di RS Bhayangkara Palembang sudah cukup baik dan sesuai dengan peraturan-peraturan yang mendasari kerjasama antara pihak RS dengan BPJS. Begitu pula dengan aspek struktur birokrasi/organisasi hampir tidak ada permasalahan terkait implementas UU Nomor 24 Tahun 2011.

\section{Rekomendasi}

Berdasarkan kondisi pelaksanaan UU Nomor 24 Tahun 2011 di RS. Bhayangkara Palembang, masih ada hal-hal yang perlu dibenahi dan diperbaiki dalam sistem pelayanan, antara lain ketidaksesuaian SDM yang ada dengan pasien yang harus ditangani setiap hari, serta selalu melakukan evaluasi untuk meningkatkan kualitas pelayanan yang sudah ada dengan memperhatikan kritik dan saran dari pasien sebagai bahan intropeksi untuk meningkatkan pelayanan yang lebih berkualitas serta kesesuaian dengan peraturan yang berlaku. BPJS Kesehatan sebaiknya bisa meningkatkan koordinasi yang lebih baik dengan pihak RS serta Dinas Kesehatan agar semua pihak dapat menjalankan tugasnya dengan baik.

\section{UCAPAN TERIMAKASIH}

Penulis mengucapkan terima kasih kepada pihak Rumah Sakit Bhayangkara Palembang, serta seluruh pihak yang bersedia memberikan data dan informasi hingga tulisan ini dapat diselesaikan dengan baik, atas kesediaannya memberikan informasi dalam penelitian ini.

\section{DAFTAR PUSTAKA}

Abidin. 2016. "Pengaruh Kualitas Pelayanan BPJS Kesehatan terhadap Kepuasan Pasien di Puskesmas Cempae Kota Parepare." Media Kesehatan Masyarakat Indonesia 70-75.

Amalia, P. 2015. Hubungan Dimensi Mutu Pelayanan dengan Tingkat Kepuasan Pasien di RSUD Dr. H. Soemarno Sosroatmodjo Bulungan Kalimantan Timur. Laporan Akhir, Padang: Universitas Andalas.

Dunn, William N. 1998. Pengantar Analisis Kebijakan Publik Implementasi . Yogyakarta: Gadjah Mada University Press.

Fahriadi. 2008. Determinan Kinerja Perawat Di Instalasi Rawat Inap Ratu Zalecha Martapura Kabupaten Banjar. Tugas Akhir, Martapura: Akademi Keperawatan Intan Martapura.

Haryadi, Devy, and Solikhah. 2013. "Evaluasi Sistem Informasi Pendaftaran Pasien Rawat Jalan di Rumah Sakit Umum PKU Muhammadiyah Bantul." Jurnal Fakultas Kesehatan Masyarakat 55-65. 
Mulyadi, Deddy, Hendrikus T Gedeona, and M Nurafandi. 2016. Studi Kebijakan Publik dan Pelayanan Publik: Konsep dan Aplikasi Proses Kebijakan Publik Berbasis Analisis Bukti untuk Pelayanan Publik. Bandung: Alfabeta.

Muninjaya, Gde. 2011. Manajemen Mutu Pelayanan Kesehatan. Jakarta: Penerbit Buku Kedokteran.

Musdalifah, and Fuad Hasan. 2020. "Pengaruh Kualitas Layanan terhadap Loyalitas dengan Variabel Kepuasan sebagai Mediasi di KPRI Makmur Kecamatan Burneh Kabupaten Bangkalan." Agriscience Vol. 1 (1) 166-185.

Peraturan Menteri Keuangan Nomor 78 Tahun 2020 tentang Peraturan Kementerian Keuangan (PMK) tentang Pelaksanaan Pembayaran Kontribusi Iuran Peserta Penerima Bantuan Iuran Jaminan Kesehatan, Iuran Peserta Pekerja Bukan Penerima Upah Dan Peserta Bukan Pekerja dengan Manfaat Pelayanan Di Ruang Perawatan Kelas III, dan Bantuan Iuran Bagi Peserta Pekerja Bukan Penerima Upah dan Peserta Bukan Pekerja dengan Manfaat Pelayanan Di Ruang Perawatan Kelas III oleh Pemerintah Pusat dan/atau Pemerintah Daerah

Rahayu, Sri. 2016. "Analisis Kualitas Pelayanan BPJS dan Kualitas Pelayanan Rumah Sakit terhadap Kepuasan Konsumen di Rumah Sakit Natar Medika Natar Lampung Selatan." Jurnal Manajemen Magister Darmajaya 173-194.

Riswan. 2020. Hubungan Kualitas Pelayanan Kesehatan terhadap Kepuasan Pasien Rawat Inap Peserta BPJS di Rumah Sakit Islam Faisal Makassar. Skripsi, Makassar: Universitas Hasanuddin.

Suparta, Haryono, and Asriani Kamsir. 2018. "Hubungan Mutu Pelayanan terhadap Kepuasan Pasien di Poli Umum Puskesmas Lompoe Kota Pare-Pare." Jurnal Ilmiah Kesehatan Pencerah Vol. 7 (1) 54-63.

Syaputra, Agus Diman. 2015. Hubungan Mutu Pelayanan BPJS Kesehatan dengan Kepuasan Pasien di Instalasi Rawat Inap Kelas II Rumah Sakit Umum Daerah Sekayu Tahun 2015. Karya Tulis Ilmiah, Sekayu: Akademi Keperawatan Kabupaten Musi Banyuasin.

Undang-Undang Republik Indonesia Nomor 24 Tahun 2011 tentang Badan Penyelenggara Jaminan Sosial.

Widada, Trisna, Agus Pramusinto, and Lutfan Lazuardi. 2017. "Peran Badan Penyelenggara Jaminan Sosial (BPJS) Kesehatan dan Implikasinya terhadap Ketahanan Masyarakat (Studi di RSUD Hasanuddin Damrah Manna, Kabupaten Bengkulu Selatan, Provinsi Bengkulu)." Jurnal Ketahanan Nasional 199-216.

Wulandari, Rizani Catur. 2018. Analisis Kepuasan Pasien terhadap Pengendalian Mutu Pelayanan Kesehatan di Rumah Sakit Haji Makassar. Skripsi,: Makassar: Universitas Hasanuddin. 